\title{
Organization-Specific Implementation of Subject-Oriented Processes
}

\section{$9.1 \quad$ To Go}

Now, we are almost done. We have a validated model and have thought about optimal process structures and utilization of resources. Now, we need to know: Who does what?

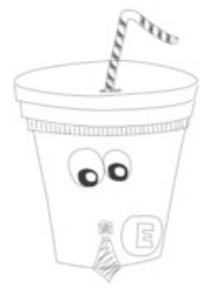

You are right. Now it comes to names. When the activities specified in a subject are carried out by a person, management and all other involved parties need to know who this person is. Instead of a single person, an entire organizational unit could also be responsible for a subject.
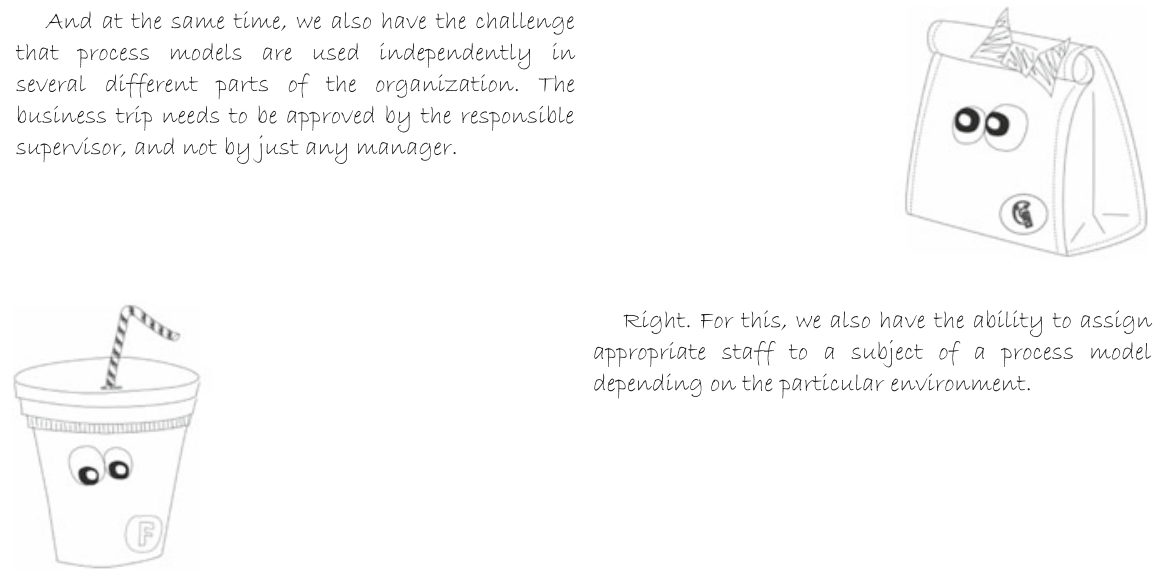

Right. For this, we also have the ability to assign appropriate staff to a subject of a process model depending on the particular environment. 
So 1 need to know the organizational context of
my process.

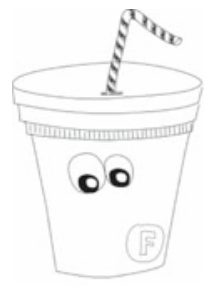

What about delegation regulations? We have repeatedly had problems with them!

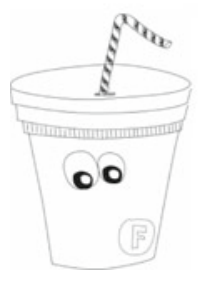

In the previous chapters, we have described how business processes of an organization are mapped to a process model by the subject-oriented method. The result is then validated and optimized as required. The process is now specified to the extent that it can be used in the organization. This step is referred to in terms of the S-BPM process model as an organization-specific implementation. With this, abstract subjects become real-life employees, the subjects are embedded into the organization.

As part of this process, however, two different "worlds" are brought together: an abstract model, and thus an artifact, is transferred to a social system. A transfer of model structures to a living system occurs. This transition requires guidance and support. Organizational developers can help here. The subject-oriented approach also helps, because the direct relation of subject specifications to humans as Actors can be used. In addition, context-sensitive business rules can be defined. 


\subsection{S-BPM Stakeholders Handling the Organization-Specific Implementation}

\subsubsection{Actors}

Employees participating in the processes under consideration were already involved in the development of the process model, including validation and optimization. They can be of great help in introducing a new or revised process. Their participation in the development of the model facilitates their individual identification with the process. In most cases, this in turn helps in achieving acceptance of the process by other affected employees. Thus, the Actors involved in modeling are an essential starting point for the organizational implementation of business processes. The other Actors become acquainted with the process and learn how to use it through these advocates.

Work performers affected by changes need to be actively engaged in the change process, to ensure their acceptance. They play a crucial rule, as they need to internalize a process to bring it to life.

\subsubsection{Governors}

The Governor is in the focus of organization-specific implementations, as he needs to make decisions with respect to personnel issues. In addition, affected managers need to be involved. They need to ensure that the existing personnel can work along the process in a target-oriented way, and they have to assign the subjects to the appropriate people. The role of Governor represents the management level, which has interest in ensuring that new processes in the organization actually work and that the employees are motivated and willing to work along them. The Governor's intent is to ensure that processes become familiar, and their benefit transparent, to the entire organization.

Finally, the Governor needs to provide the necessary resources to qualify, when necessary, people taking on new tasks in processes.

\subsubsection{Facilitators}

A Facilitator accompanies the entire process of organization-specific implementation. He ensures, in cooperation with the Governor, that the concerned managers identify the appropriate people for a subject, and that these people are informed about their respective tasks in the process. The affected employees also need to be trained accordingly, if necessary. The development of required training programs is designed and prepared by the Facilitator, along with those Actors already involved. For this, it may also be necessary to involve Experts. 


\subsubsection{Experts}

A key Expert in organizational implementation is the consultant for organizational or personal development. For upcoming changes, specialists should be involved who accompany the introduction or revision procedure. They develop measures for informing the employees specifically about the innovation or change, and try to motivate. Various media can support this process in a target-oriented way, such as the use of wikis, which could store important process information available to Actors. Furthermore, workshops can help to make employees familiar with the process changes.

\subsection{Embedding Subjects Into an Organization}

\subsubsection{Mapping Subjects to Subject Carriers}

Subjects are abstract active resources in S-BPM. They represent Actors or systems in a process that initially have nothing in common with actual entities, such as people or IT systems. It is only during the implementation of a process that abstract subjects are assigned to specific individuals, groups, or systems, termed subject carriers in the context of subject orientation. This chapter deals with the assignment to individuals, while the assignment to technical systems is discussed in Chap. 10.

Using the example of the business trip application, we describe for human actors, how the three subjects "employee", "manager", and "travel office" are embedded into the organization. We assume the simple organizational structure as shown in Fig. 9.1.

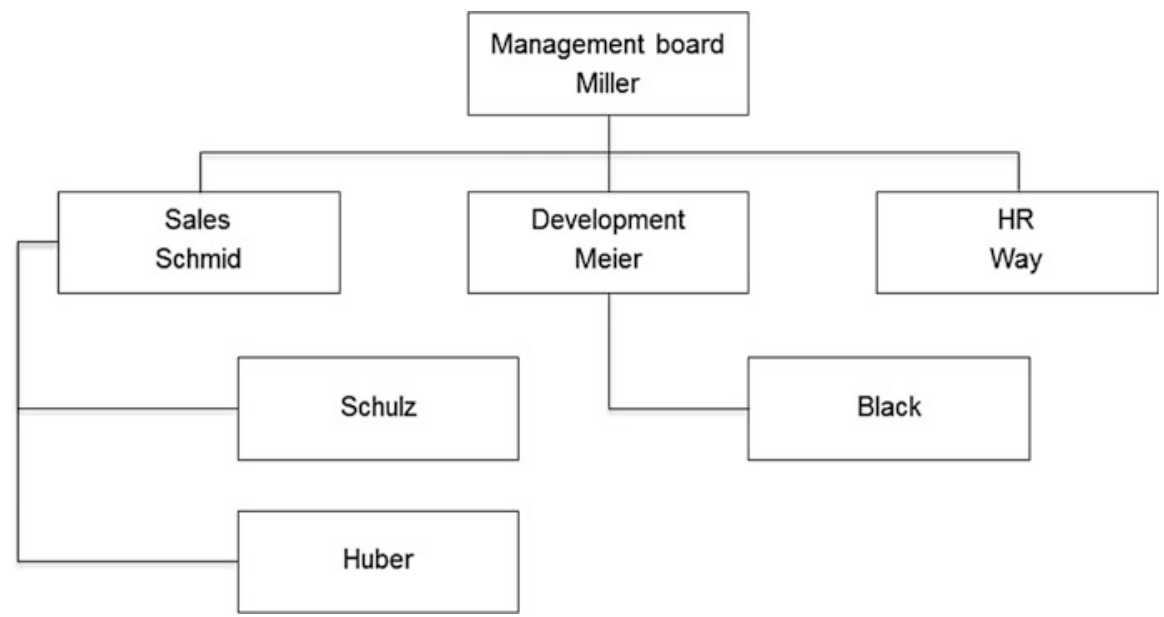

Fig. 9.1 A simple organizational chart 
In this structure, e.g., Mr. Schulz from the sales department issues a business trip request. Mr. Schmid as his manager approves it, and Mr. Way as a representative of the travel office in the human resources department (HR) is responsible for organizing the trip. Figure 9.2 shows how the subjects are assigned to the respective subject carriers.

\begin{tabular}{|c|c|c|c|}
\hline Subject & Subject behavior & Subject carrier & Organizational unit \\
\hline Employee & is transferred to & Mr. Schulz & Sales \\
\hline Manager & is transferred to & Mr. Schmid & Sales \\
\hline Travel office & is transferred to & Mr. Way & HR \\
\hline
\end{tabular}

Fig. 9.2 Subject mapping table for the business trip request of Mr. Schulz

Figure 9.3 shows the processing of the process instance "business trip request" of Mr. Schulz' according to the organization-specific embedding.

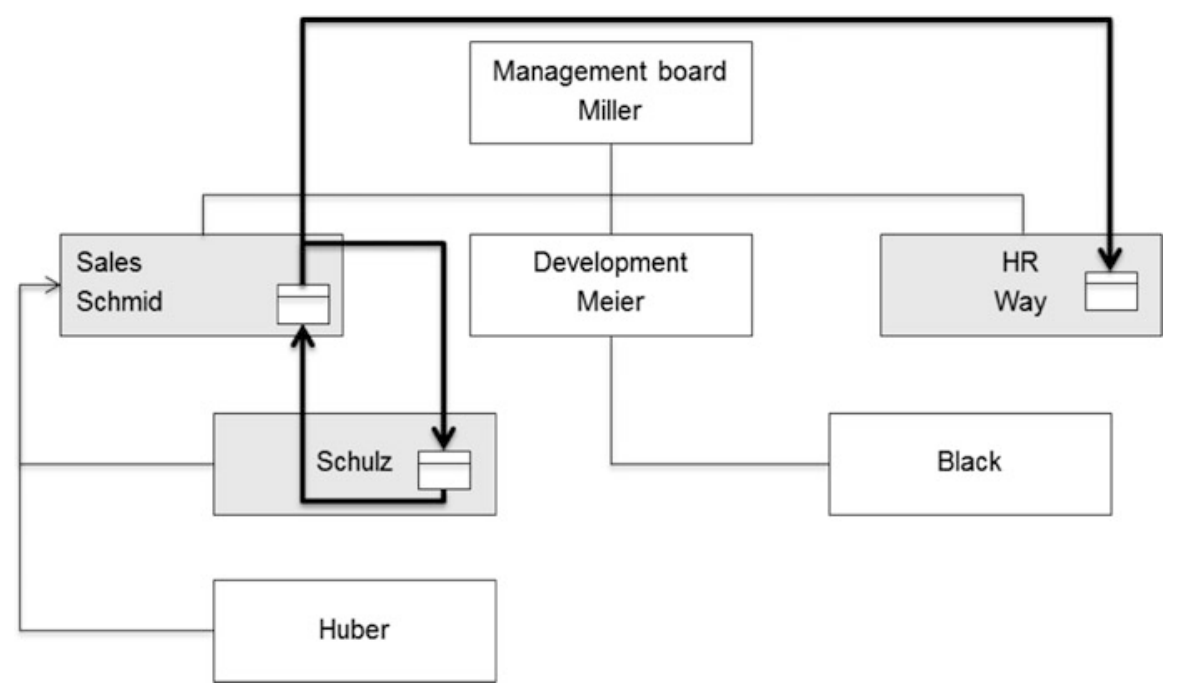

Fig. 9.3 Embedding the subjects of the business trip request of Mr. Schulz

With this, the organization-specific implementation of this simple example is initially completed. However, it quickly becomes obvious that in practice we have to consider the following aspects, which we subsequently describe in more detail:

- Firstly, the mapping reveals that only the business trip request of Mr. Huber can be handled analogously to Mr. Schulz's. In contrast to Mr. Schulz, Mr. Black's manager is Mr. Meier. Therefore, he has to be put in a different organizationspecific context (see Sect. 9.3.2). 
- Secondly, a direct assignment of a (single) concrete subject carrier to a subject is usually not advisable, since work overload or lack of availability could impede, or even prevent, process execution. This leads to the introduction of subject carrier groups (see Sect. 9.3.3) and delegation regulations (see Sect. 9.3.4).

The basic principle of intelligible modeling is of crucial importance for organization-specific implementation. A model is only beneficial if it is understood by all concerned participants.

\subsubsection{Considering the Organization-Specific Context of a Subject Carrier}

Usually, it is not sufficient to assign only one subject carrier to a subject, because a process inherently should be able to be run by several people in different places in the organization. For example, Mr. Schulz will not be the only one who is going on business trips. So there will be multiple applicants, who usually have different supervisors approving the request. The execution of a process instance therefore depends on the organization-specific context of the subject carrier. This is determined by the initiator of the process (start subject) when instantiating a business trip application, so in our example by the employee as an applicant.

In Fig. 9.4, the organizational context of the employee Black as the applicant is given. In this case, Mr. Meier is his manager. The travel office, on the other hand, is still represented by Mr. Way.

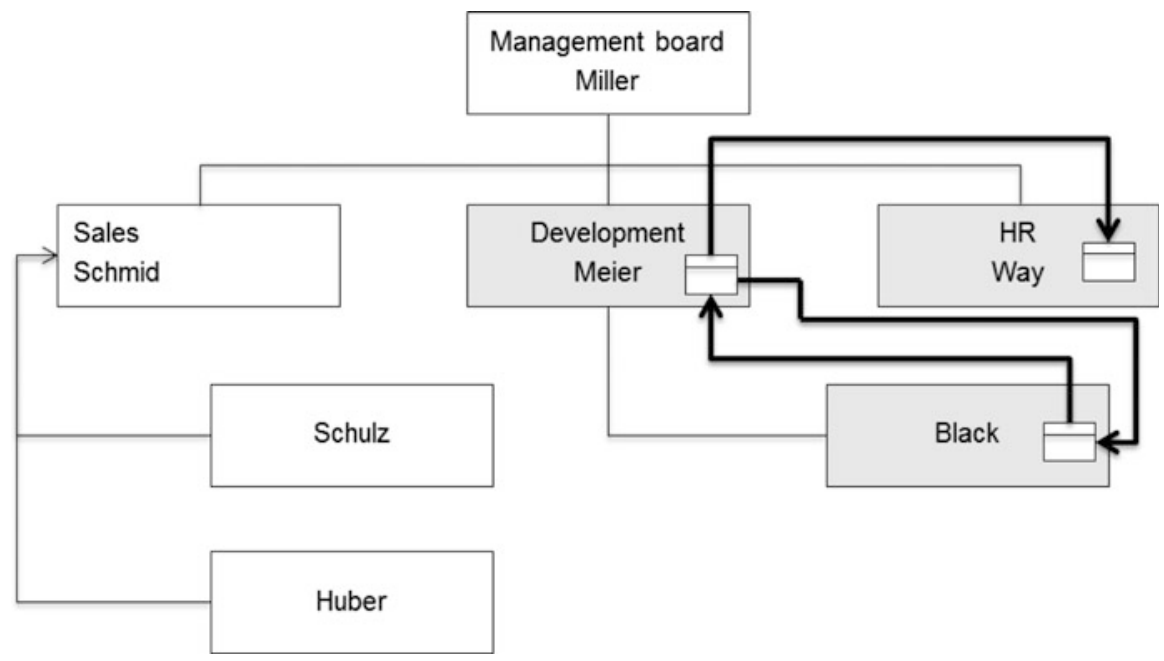

Fig. 9.4 Embedding the subjects into the business trip request of Mr. Black 
The organization-specific contexts for the employees at different hierarchical levels reporting to Mr. Miller in the business trip application process (as shown in the organization chart) can be represented in tabular form (see Fig. 9.5).

\begin{tabular}{|l|l|l|}
\hline $\begin{array}{c}\text { Employee start } \\
\text { subject }\end{array}$ & \multicolumn{1}{|c|}{$\begin{array}{c}\text { Manager in } \\
\text { organizational context }\end{array}$} & $\begin{array}{c}\text { Travel office in } \\
\text { organizational context }\end{array}$ \\
\hline Miller & Miller & Way \\
\hline Schmid & Miller & Way \\
\hline Meier & Miller & Way \\
\hline Schulz & Schmid & Way \\
\hline Huber & Schmid & Way \\
\hline Black & Meier & Way \\
\hline Way & Miller & Way \\
\hline
\end{tabular}

Fig. 9.5 Context table of the business trip application process for the shown organization structure

Context tables allow representing relevant rules and factors for the situationsensitive processing of business objects in a comprehensive and structured way when embedding processes in organization-specific settings.

According to the table, Mr. Way is subject carrier for both the subject "employee" and the subject "travel office". Consequently, he himself can also apply for business trips, and he not only processes the approved applications of his colleagues but also his own. It is also apparent that Mr. Miller as CEO has, at least in this context, no superior, and therefore is allowed to approve his own business trip applications.

The example of Mr. Way shows that people are usually involved as subject carriers in multiple processes. They can have a specific context for each of these processes. Mr. Schmid and Mr. Meier also represent two subjects in the example. On the one hand, they are employees of Mr. Miller and in this context can apply for business trips with him as their superior. On the other hand, they are themselves managers of Mr. Schulz, Mr. Huber, and Mr. Black, respectively, and need to approve their requests. 


\subsubsection{Mapping Subjects to Subject Carrier Groups}

Instead of assigning a subject specifically to a single person as subject carrier, it can also be mapped to an organizational unit, a role, a committee, or the like. In such a case, we speak of an assignment to a subject carrier group.

This possibility is important in practice, because in operational reality a process is run at any particular point in time multiple times in parallel, i.e., many process instances occur per time unit (e.g., per day). For processing these within a specified timeframe, operational managers obviously engage a number of people who can process the instances or parts thereof in parallel.

In large organizations with many business trip applications per day, assigning only a single person to the travel office would only allow processing applications sequentially and therefore lead to a bottleneck. As a consequence, applicants would have to wait a relatively long time for the feedback of the travel office with regard to the completed bookings. So instead of assigning the subject "travel office" only to the subject carrier Mr. Way, the organizational developer maps the subject to a predefined subject carrier group "employees of travel office”. Besides Mr. Way, the subject carrier Mr. Longway is also part of this group (see the grayed elements in Fig. 9.6). Basically, two people are then available to process business trip applications. This enables the parallel execution of processes. The assignment of members to the subject carrier group determines its capacity, and as such, also the capacity of its assigned subject.

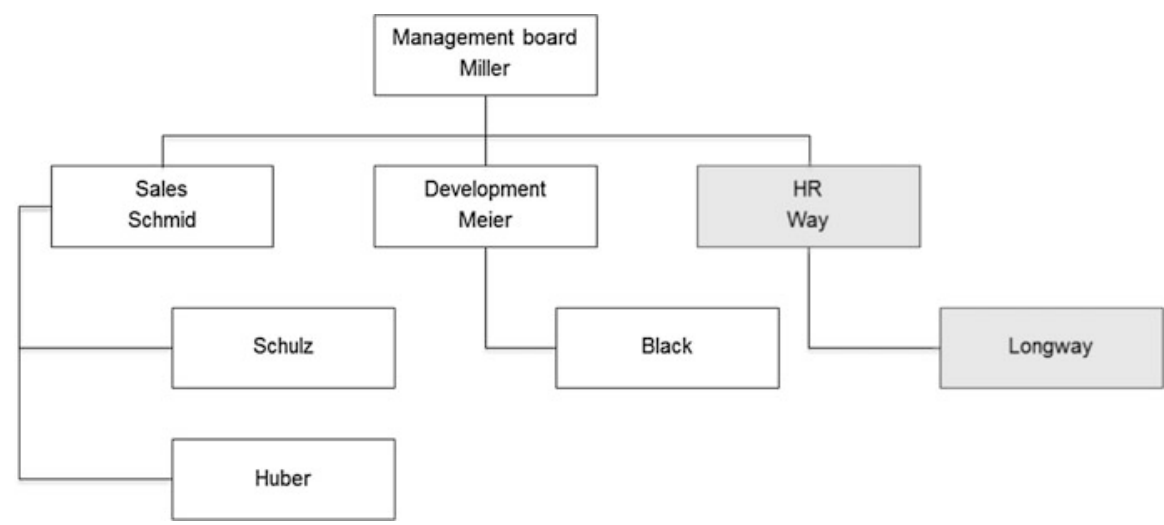

Fig. 9.6 Organization structure with subject carrier group "employees of travel office"

In order to implement this change, the operation manager only needs to replace in the context table of Fig. 9.5 in the column "travel office in organizational context" the entry for the subject carrier "Way" by the subject carrier group "employees of the travel office". In case the responsibility for processing business trips for the management board should remain exclusively with Mr. Way in the travel office, he remains as subject carrier in the row of Mr. Miller. 
The outlined context tables need to be specified for each process of an organization. Since in reality individuals are involved in diverse roles in many different types of processes, subject carriers and subject carrier groups occur in many of these tables and also in different columns, respectively. Depending on their various tasks, individuals are assigned to multiple subject carrier groups.

This type of organization-specific implementation of processes is very flexible, as organizational changes, such as changing the role of a person, can easily be accomplished at a fine-grained level. For example, an employee needs only to be assigned to one of the corresponding subject carrier groups. The context table of the affected process remains unchanged.

The various context tables can be interpreted as superimposed organizational charts. Thus, this methodology enables a precise but simple mapping of the usually complex organizational structures in reality.

Still pending is the question of how to determine which individual, initially not specified subject carrier within a group, executes the associated subject behavior when an instance is created at runtime, or an instance step has to be performed. This requires the definition of rules by organizational developers. Selected examples in this regard are:

- Freedom of choice: Instances are pooled prior to the respective processing stations. Any member of the subject carrier group takes one instance, another group member takes another one, etc. The Actors coordinate their activities and decide themselves according to the principles of the subject orientation on the assignment of each case.

- Determination by dispatcher: A dispatcher as a dedicated subject carrier (Governor) inside or outside the group assigns the instances to the group members for processing. With the support of a workflow solution, a process engine takes this role (see Chap. 10). Criteria in both cases could be based on various aspects, such as the general availability or the workload of Actors and the nature of the business objects (see Sect. 9.3.5).

Each organization can consider whether it makes sense to only exclusively assign subjects to subject carrier groups which, in effect, must have at least one subject carrier as a member. This would ensure in a straightforward way from the very beginning the scalability of processing capacity. The group could accommodate additional human resources, if required. A direct mapping of a subject to a person would still be possible if the subject carrier group, as an exception, contains only one subject carrier. The only disadvantage of this approach would be an additional, actually unnecessary step in the dissolution of the organizational context at runtime (subject $\rightarrow$ subject carrier group $\rightarrow$ subject carrier, versus subject $\rightarrow$ subject carrier).

Functional roles and organizational units are implemented in S-BPM through subject carrier groups. 


\subsubsection{Considering Delegation Regulations}

Another requirement from the practice for the organizational integration of processes is the regulation of delegations. This is particularly relevant in cases in which a subject is not assigned to a subject carrier group, but to a concrete subject carrier. The absence of people should not lead to unplanned delays in the execution of process instances. For the organization-specific implementation of a process model, it is therefore necessary to ensure that its execution does not depend on individual subject carriers, but rather is ensured by delegates in case assigned authorized people are not available. By specifying delegates, people responsible for the organization or subject carriers themselves can avoid delays in executing process instances when a subject carrier responsible for an upcoming process step is not available, e.g., due to illness.

In the example of the business trip application, a delegate of Mr. Schmid needs to be determined to act as manager. Otherwise, applications from Mr. Schulz and Mr. Huber could not be approved if Mr. Schmid is not available. Therefore, Mr. Meier is authorized as Mr. Schmid's delegate to process business trip requests, which is expressed by the dashed additions in Fig. 9.7. Alternatively, Mr. Miller can be modeled, as the next higher manager in the line organization, as the delegate of Mr. Schmid. However, this could be undesirable for business trips, because the management board would have to spend an unnecessary amount of time for such administrative tasks.

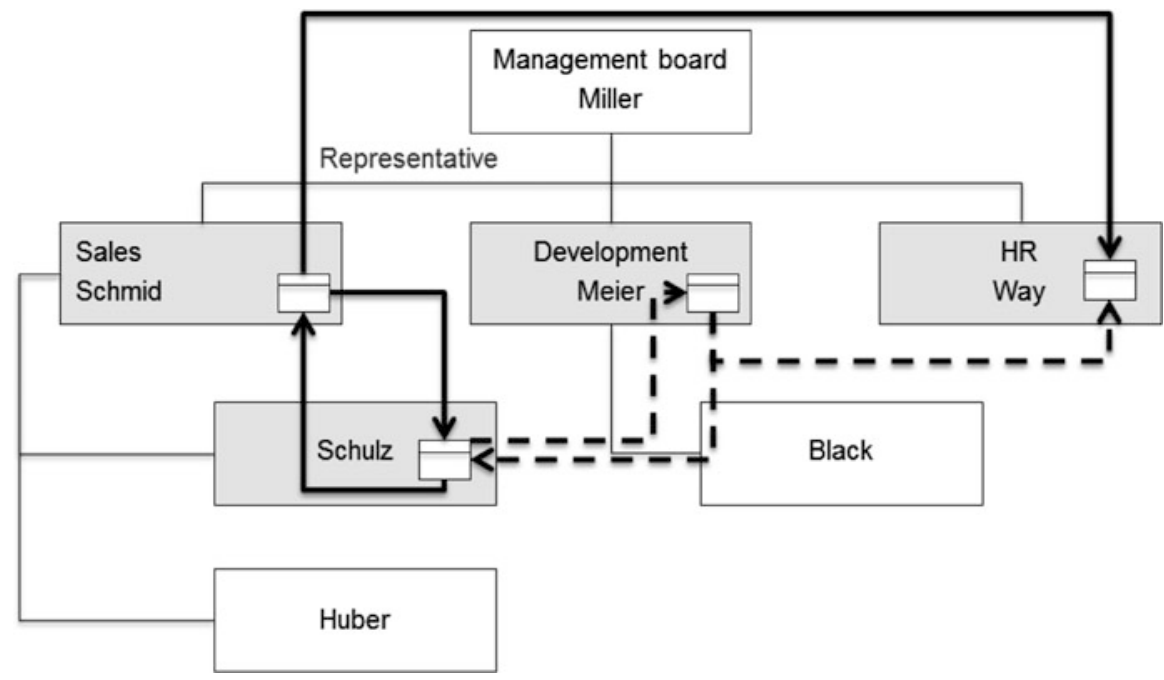

Fig. 9.7 Delegation regulation Schmid/Meier for processing business trip requests of Mr. Schulz

Since Mr. Schmid is subject carrier for several different subjects in different processes, we need to assign to him different subject carriers or groups as delegates for his tasks in each process. Mr. Schmid is already involved in the business trip application process in the form of two subjects (employee and manager). Because 
of his responsibility for sales, he will also represent subjects in sales processes. This needs to be reflected in the delegation regulations. His disciplinary delegate as manager for business trip requests could be Mr. Meier, as previously shown. Functionally however, e.g., in the sales process of bidding, he could be represented by a member of his organizational unit, such as Mr. Huber.

By concatenating the representation logic, we could also cover cases where not only the Actor of a functional process, but also his (primary) delegate, is not available. In such cases, the delegate of the delegate needs to step in.

For the implementation of flexible delegation regulations, the organization responsible can again utilize the instrument of subject carrier groups. It could make sense, e.g., to define a group containing all managers of a particular hierarchy level (e.g., heads of department - in the sample organization chart Mr. Schmid, Mr. Meier, and Mr. Way). In the absence of one of the three people, each of the other two would then be authorized to sign business trip applications for his employees, and thus, act as a delegate. The actual allocation at runtime can be done similarly to the procedure described in Sect. 9.3.3. In doing so, the subject carrier group "area manager" is specified, rather than Mr. Meier, as a delegate for Mr. Schmid.

The delegate regulation is another aspect of the organization-specific context of embedding subjects into an organizational structure. Finally, when implementing this structure, we need to clarify who, and under what conditions, is allowed to activate a delegation regulation. For planned absences such as vacations, business trips, or training, Actors can determine for themselves who takes their role(s) as subject carrier. For unplanned absence, e.g., due to illness, the administration needs to dynamically determine a subject carrier or a subject carrier group as a delegate.

\subsubsection{Considering the Context of Business Objects}

In addition to the subjects, also the content of the business objects can be considered in the course of organization-specific implementation. The subject carrier or the subject carrier group is determined in this case through values of one or more business objects occurring in the instance.

For a business trip request, it could be that an employee in the travel office, Mr. Longway, is specialized in international travel and therefore is handling respective questions (like visas, mobility, etc.). In this case, it would be useful to assign applications for business trips abroad to Mr. Longway as subject carrier. The destination country would then represent a business object context for the business trip application. The necessary information can be dynamically derived at runtime of an instance from the object (e.g., value of the data element "destination country" unequal Germany).

Figure 9.8 shows this type of embedding. Mr. Schulz applies for a trip within Germany and for a trip abroad. Both are approved by his superior, Mr. Schmid. Then, the first application is forwarded for further processing to Mr. Way, whereas Mr. Longway organizes the international travel. The path of the request for the foreign trip is marked by the dashed lines. 


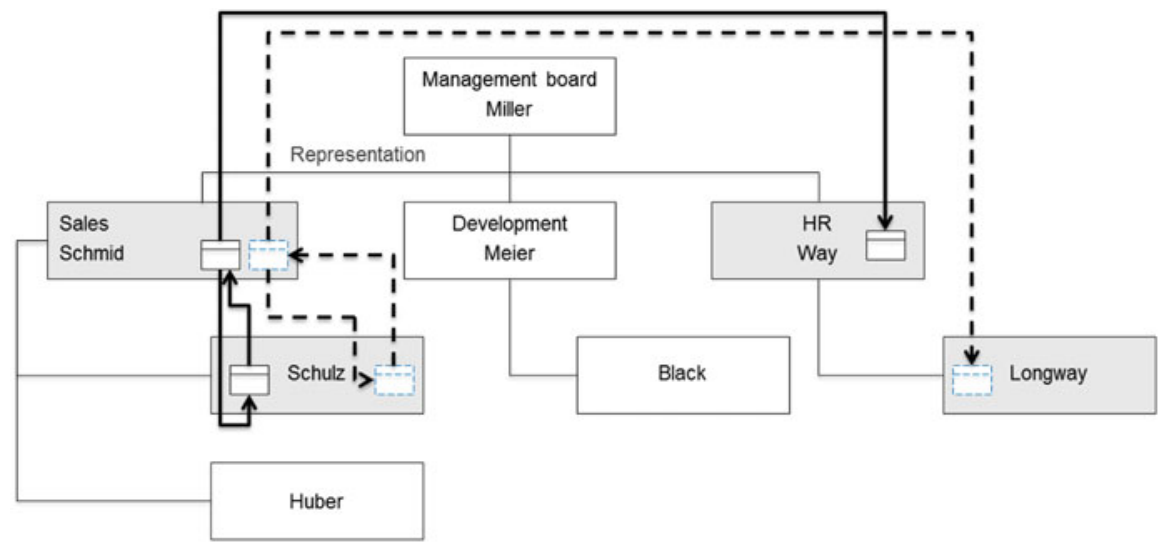

Fig. 9.8 Determining subject carriers from business object context at runtime

Such a distinction leads to a change in the context table (see Fig. 9.9). If it should apply to all applications in our example, the if-then clause needs to be inserted in all table rows. This case demonstrates the implementation of business rules relevant to

\begin{tabular}{|l|l|l|}
\hline \multicolumn{1}{|c|}{$\begin{array}{c}\text { Employee (start } \\
\text { subject) }\end{array}$} & Manager in organizational context & \multicolumn{1}{c|}{$\begin{array}{c}\text { Travel office in organizational } \\
\text { context }\end{array}$} \\
\hline$\ldots$ & $\ldots$ & $\ldots$ \\
\hline Schulz & Schmid & $\begin{array}{l}\text { If requested destination country = Germany, } \\
\text { then Way, otherwise Longway }\end{array}$ \\
\hline$\ldots$ & $\ldots$ & $\ldots$ \\
\hline$\ldots$ & $\ldots$ & $\ldots$ \\
\hline
\end{tabular}

Fig. 9.9 Extract of the context table including dependencies on a business object

a particular organization.

In large organizations, a further distinction between responsibilities for different countries could make sense. For example, the organization responsible for the travel office could form subject carrier groups for China, USA, etc. and assign to them proper specialized staff. In the if-then clauses, we would then need to replace the actual names of the subject carriers by the corresponding subject carrier group names.

\subsection{Embedding Behavior}

Subjects are defined by their behavior and communication with other subjects. This abstract behavior is transferred to actual behavior in reality. Subject carriers as holders of positions in the organizational structure implement the abstract behavior with their qualifications (skills) and suitable tools. 


\subsubsection{Adjustment of the Tasks in Job Descriptions}

Job profiles document roles and responsibilities of employees. In the allocation plan, all activities that an organization provides are described. After having specified the real people involved in a process by assigning subjects to subject carriers, the job profile of the assigned subject carriers may need to be adjusted. Job tasks could be added or removed, which therefore needs to be documented accordingly in the job description.

For instance, in case the job profiles of the managers do not yet explicitly include the approval of business trips, because it was taken for granted, it should be added now. When the booking of business trips has previously been down by team assistants and this is no longer required due to the establishment of the travel office, this task needs to be removed from the profile of the team assistants.

The adjustments in the job description are of particular importance when salary depends on certain profiles in collective or other contracts. A change can then actually result in the assignment of a subject carrier as holder of a position to another wage group. Such environmental conditions need to be recognized when embedding a process. They can lead to a respecification of subjects, which in turn may lead to a far-reaching modification of the process itself.

Job profiles may concern several subjects. Thus when embedding subjects, the specific capabilities of individual position holders need to be considered and coordinated accordingly.

\subsubsection{Design of the Work Environment}

For successful task accomplishment, an adequate working environment needs to be established. In all processes in which people, with their associated tasks and decisions, influence the results of process performance, workplace design plays a critical role. Initially, this is related to the spatial conditions (size, location, lighting, etc.) and interior design (furniture, pictures, plants, etc.). A second aspect concerns the equipment, primarily IT systems that people are provided with to perform their tasks along the process at hand (see Chap. 10). Catalysts to increase motivation and performance are especially ergonomically advanced solutions, such as intuitive, accessible user interfaces, or personalized portals with single sign-on. Compliance with government regulations is mandatory, e.g., limits for radiation from computer monitors.

When designing the work environment, the temporal dimension requires attention, i.e., appropriate measures must be taken in time, so that a smooth implementation process is not impeded. For example, it may be useful to locate people (as subject carriers) with mutually intense communication in close proximity to each other. This holds particularly true when communication occurs via traditional paper and interoffice mail. 
Equipping the travel office with work supplies concerning the business trip application process could include the provision of timetables, hotel directories, city maps, etc., or, respectively a facility to access similar online sources of information.

\subsubsection{Coordination of Required Competencies}

In order to perform their tasks as defined in a process, subject carriers need to have certain skills. The necessary skill sets are explained in the sequel.

Functional Expertise

As characteristic feature of process specifications, different key personnel collaborate to achieve a result in terms of added value for an organization. It is usually not a goal that all people perform all the functions of the subjects, but rather that specialists cooperate for task completion. Each specialist needs specific expertise to accomplish his tasks. Even if merely an approval is requested in a process, thorough knowledge is required with respect to the concerned object for approval and potentially relevant internal and external rules and regulations, etc.

Some approaches try to incorporate, as part of a process-oriented knowledge management approach, tacit knowledge in form of context information of a process (cf. Abecker et al. 2002). In S-BPM, this knowledge is encapsulated in subjects, and as a rule, does not need to be explicitly documented. Functional expertise is certainly required in order to perform the expected subject behavior in a responsible way.

In the sample business trip application process, subject carriers of the travel office are expected to have, among other things, a sound standing knowledge of current travel legislation and associated case law.

\section{Process Skills}

Each subject carrier needs to know the fundamentals and the context of his own process. These include:

- Process overview: Each subject carrier should know the aims and importance of his process for the organization.

- Own responsibilities in the process: Each subject carrier needs to know his duties within the given process and be able to assess his contribution for completing the process.

- Communication partners: Each subject carrier must know its communication partners in process execution.

- Business objects: Each subject carrier must know the range of business objects available to him for task accomplishment.

Process skills for the business trip application process means in this sense that the employees know the purpose of an application and its procedure: What do I have to do myself, what do others do for me? To whom do I send my application? What happens with it? Which form do I use?

In such simple processes, it is usually sufficient that the Organization Department is in possession of a freely accessible process documentation, which contains 
the aforementioned information and makes the procedures transparent. For complex processes, additional in-house training and training-on-the-job are required so that participants can acquire process skills.

Tool Skills

In order to perform their tasks, stakeholders involved in the process are provided with information and communication technology tools, e.g., to edit and share business objects (see Chap. 10). These may be office applications, ERP systems, e-mail, telephone, or workflow management systems.

In terms of efficient task completion, the employees need skills for the appropriate use of these tools. For dealing with software and devices, e.g., they need to be adequately trained in time. In particular, software functionality should not only be taught in an isolated fashion, but also in the context of daily work routines along the process, otherwise process stakeholders may develop their own (partial) solutions with end-user tools, such as Microsoft Excel. These solutions are often defective and difficult to integrate into the overall process execution.

\section{Communicative Competence}

Each process is characterized by communication between the individually assigned subject carriers. This means that the people involved in the process need to exchange messages with each other. For each human interaction, a proper communication channel and partner has to be identified. Business communication, including e-mail or electronic forms, needs to meet minimum requirements for appreciation, clarity, style, and communicative behavior. A business trip request of an employee such as "Wonna fly to London next week!" is not very likely to be approved by the supervisor, not only due to serious flaws in the specification but also due to the choice of words.

\section{Social Skills}

A process model can be considered as a template for procedural specifications. However, during its implementation and execution, there may be interventions and disturbances, which need to be clarified. Social competence is particularly required when external disturbances need to be eliminated. In such cases, all involved process parties have to cooperatively adopt appropriate measures to nevertheless achieve the desired process result. All participants need to be willing to resolve conflicts and to hereby apply the necessary social skills (e.g., conflict resolution and ability to work in a team). They should be willing to share responsibility and to think and act in terms of the overall team perspective.

\subsubsection{Change Management in S-BPM}

In the course of organization-specific implementation, a model is transferred to the realities of an organization. This leads to changes in the organization; employees have to learn new behavior patterns or dismiss existing ones. Often, projects fail at this step. The inertia of the organization is sometimes so strong that the implementation of new processes fails (cf. Best et al. 2007, pp. 183 ff.). 
To avoid or at least reduce problems of acceptance by those affected, which could impede a successful implementation, changes should be carefully prepared and accompanied by an appropriate change management as part of process management. Measures to this respect are, e.g., open communication, changes actively exemplified by management, and encouragement for individual initiative of employees, or in other words, contributions to the active development and promotion of an S-BPM culture (see Sect. 3.6.3.3). For details, procedures, etc. of change management, readers can refer to various resources such as Doppler (2003) and Hirzel and Kuhn (2008, pp. 247 ff.).

For acceptance, especially those Actors, who were involved in the redefinition or modification of a process, play a major role. They can most credibly convey that a new process will deliver a benefit, and therefore these Actors can represent important promoters of an organizational development project.

Usually, organizational change processes open up development fields that require special attention because of avoidance strategies. Therefore, change management needs to rationalize the reactions of employees to change. It is therefore beneficial in the process of change to start at the point of formal changes for each employee, namely with his duties and his job description. S-BPM enables this, since it moves the responsible authority of work activities to the center of change. Hence, in case a process is described in a subject-oriented way, it is much easier to identify the starting point for change processes. The direct relation between subject and work authorities supports a targeted approach.

Another advantage of the subject-oriented approach is that the subject carriers have already been involved as Actors in the previous bundles of activities. Due to this involvement, a change process is likely to be able to be completed in a socially acceptable way. The participants are already familiar with the objectives and details of the organizational development project. In most cases, this positively affects their acceptance behavior.

\section{References}

Abecker, A., Hinkelmann, K., Maus, H., Muller, H., Geschäftsprozessorientiertes Wissensmanagement, Berlin/Heidelberg 2002.

Best, E., Weth, M., Geschäftsprozesse optimieren, Wiesbaden 2007

Doppler, K., Der Change Manager, Frankfurt/Main 2003.

Hirzel, M., Kuhn, F., Gaida, I., Prozessmanagement in der Praxis, Wiesbaden 2008.

Open Access. This chapter is distributed under the terms of the Creative Commons Attribution Non-commercial License, which permits any noncommercial use, distribution, and reproduction in any medium, provided the original author(s) and source are credited. 